\title{
Library tries to rebuild flooded collection
}

[WASHINGTON] The library at Colorado State University (CSU) at Fort Collins, Colorado, is seeking help from the academic community as it tries to recover from a flash flood that devastated the library's collection.

The flood, which killed five people in Fort Collins, broke through a basement wall of the Morgan Library on the night of 28 July, and rapidly rose to ceiling height. More than 425,000 volumes were being stored in the basement - more than usual, because of renovations taking place elsewhere in the library.

Among the damaged materials were bound volumes of more than 18,000 journals, supporting CSU's strong academic programmes in the sciences, agriculture and forestry.

At least 10 per cent of the damaged volumes were declared unsalvageable in the days following the flood. The rest - some 380,000 volumes - have been sent to the disaster recovery company DRS, Inc. in Fort Worth, Texas, for cleaning, reshaping and freeze-drying.

Although the company estimates that 80 per cent or more of this material can be saved, it will be two years before the last item is returned to CSU - which is too long

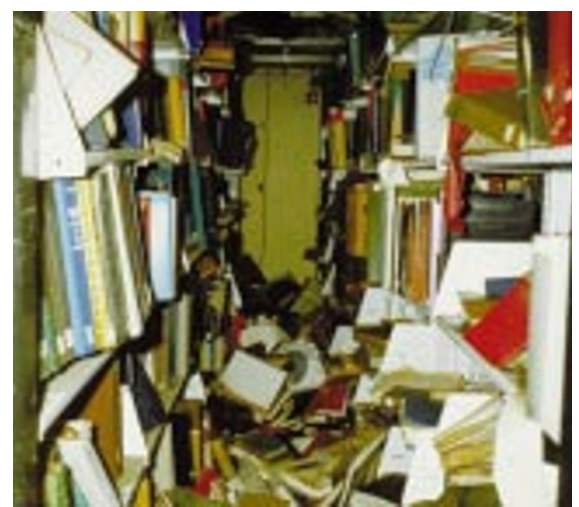

After the flood: around 380,000 volumes from the library at Colorado State University have been sent for recovery following the flash flood that breached a basement wall of the Morgan Library.

to wait, according to the librarian's collection development officer, Joel Rutstein.

"Twenty per cent is not salvageable, but we don't know which they are. And we can't wait to find out."

"There's no precendent for this," Rutstein says of the loss. No academic library in the United States has lost "the meat of its collection" in this way, he says.

CSU's collection serves an important role for the state at Colorado. "Eleven of our 13 programmes of excellence were affected we're the only institution in Colorado collecting in those areas," says the dean of libraries, Camila Alire.

CSU estimates the total damage to the campus at \$100-\$125 million, up to half of which is accounted for by damage to the library and its contents. Although the university will recover most of this money from insurance, or from the state and federal governments, much of the library's collection - including back-runs of most journals - cannot easily be re-purchased. The library is accordingly asking for donations of journals and monographs, and has set up a Web site - http://www.coalliance.org/ csuflood/csuflood.shtml — to coordinate offers.

More immediate help has been forthcoming from other libraries. Many of them have undertaken to give priority to requests from CSU for inter-library loans, and several database services have donated subscriptions.

As for the longer-term prospects, "since we set up the Web site, we've been overwhelmed with responses", Rutstein says. "Although I hate to use the metaphor, offers have gone from a trickle to a tidal wave."

LauraGarwin 